\title{
El Niño signals contained in precipitation at the East China Sea
}

\author{
You-Soon Chang ${ }^{1, *}$, HuiSoo An ${ }^{2}$, DongChull Jeon ${ }^{3}$, Jae-Cheol Nam ${ }^{1}$, Jang-Won Seo ${ }^{1}$ \\ ${ }^{1}$ Marine Meteorology and Earthquake Research Laboratory, Meteorological Research Institute, Seoul 156-720, Korea \\ ${ }^{2}$ Department of Earth Science Education, Seoul National University, Seoul 151-742, Korea \\ ${ }^{3}$ Ocean Environment and Climate Division, Korea Ocean Research and Development Institute, Ansan PO Box 29, \\ Seoul 425-600, Korea
}

\begin{abstract}
In general, El Niño signals can be easily identified in the tropical Pacific Ocean but not in the East China Sea, due to the complexity of the monsoon system and insufficient knowledge of El Niño effects in mid-latitudinal regions. In this study interannual variability of precipitation at the East China Sea is analyzed. Regional correlation and the spatial distribution of interannual variation of precipitation are also analyzed in order to confirm the teleconnection pattern. Most of the rainfall stations located in the southern area of Korea show significant biennial and interannual cycles with 2 to $8 \mathrm{yr}$ periodicity. As for the wavelet analysis, it was found that the periods of significant maximum power spectrum corresponded with historical El Niño episodes, especially when a strong El Niño/La Niña was repeated. Maximum positive correlation appears between the Niño3 region (equatorial eastern Pacific) and the East China Sea at a time lag of about 4 mo. This correlation tendency can be confirmed in the second mode of Empirical Orthogonal Function analysis explaining the strong El Niño event. These results also suggest variation in upper wind fields such as the Hadley circulation and East Asia jet stream.
\end{abstract}

KEY WORDS: Precipitation · El Niño $\cdot$ Teleconnection · Wavelet $\cdot$ Correlation $\cdot$ EOF $\cdot$ Upper wind

\section{INTRODUCTION}

El Niño is one of the most prominent natural phenomena in the tropical Pacific Ocean with a quasiperiod of 2 to $7 \mathrm{yr}$. After the catastrophic El Niño event in 1982-1983, various oceanic and atmospheric dynamics were suggested to explain the dynamics and cycle of the El Niño using ocean global circulation models (OGCMs), atmospheric global circulation models (AGCMs), coupled atmospheric-oceanic models and various statistical models.

However, those researchers were limited to only explaining the mechanism near the tropical Pacific and the coastal regions of the eastern Pacific, in spite of the importance of El Niño, which has global teleconnection, as a primary factor of global climate change (Horel \& Wallace 1981, Rasmusson \& Wallace 1983, Glantz et al. 1991). It is extremely difficult to forecast the impact of an El Niño in mid- or high-latitudinal regions because climate dynamics are governed not only by the variation of sea temperature, but also by the instability and nonlinearity of the atmosphere itself (Lorenz 1984). Peculiarly, previous studies about large-scale variability relative to El Niño seem to have excluded precipitation since it is affected by many geographical effects. Up to the present, most studies with long-term precipitation have focused only on the regional aspects of rainfall variability. Some earlier studies on global rainfall interrelationships were carried out by Kidson (1975), Stoeckenius (1981), Ropelewski \& Halpert (1987), Kane (1997) and Lau \& Sheu (1998). However, possible interrelationships between rainfall anomalies over oceans and over other regions are not well documented.

Therefore it is quite meaningful to analyze the periodicity of precipitation and regional correlation be- 
tween the equatorial region and the East China Sea, a mid-latitudinal region. This study may represent El Niño signals included in the variations of precipitation and the other atmospheric conditions over the East China Sea.

\section{DATA AND ANALYSIS METHODS}

Precipitation over the East China Sea, including southern coasts of Korea, is analyzed from in situ raingauge measurements made by the Korea Meteorological Administration (KMA 1995). To confirm the larger-scale variability of precipitation, we have utilized the precipitation data set from Xie \& Arkin (1997), called the Climate Prediction Center (CPC) Merged Analysis of Precipitation (CMAP) for the period of 1979 to 1999. Upper level wind data also are examined with the reanalysis data from the National Centers for Environmental Prediction (NCEP) for the same period of CMAP data.

The purpose of the data analysis in this study is to draw out the interannual cycle related to the El Niño period from raw time series data by using low-pass filter (semi-cosine Hanning filter) which has a cut-off frequency shorter than $2 \mathrm{yr}$, and then to analyze the interannual periodicity in detail. In order to compare the relative spatial variation of the precipitation, all data are standardized by calculating deviations from the average.

The Fourier transform has been a major tool for investigation of the temporal structure of many time series data. However, Fourier analysis cannot calculate signal evolution in time. To compensate for this weak point, wavelet transform is used in this study. Wavelet analysis is known to be a useful tool for analyzing time series which include many different timescales or changes in variance. The wavelet transform procedure is as following (Meyers et al. 1993, Webster et al. 1998). In this study, as a mother wavelet $g(t)$, the Morlet Wavelet in the form of a Gaussian function is used:

$$
g(t)=\mathrm{e}^{t^{2} / 2} \mathrm{e}^{+i c t}
$$

To apply a different scale, a daughter wavelet $\left(g_{a \tau}\right)$ is calculated:

$$
g_{a \tau}=\frac{g}{\sqrt{a}}\left(\frac{t-\tau}{a}\right)
$$

The translation parameter $(\tau)$ and dilation parameter (a) correspond to the time and length scales of temporal period, respectively. The convolution of raw time series $f(t)$ with the set of wavelets is the wavelet transform $X_{g}(\tau, a)$ :

$$
X_{g}(\tau, a)=\frac{1}{\sqrt{a}} \int g\left(\frac{t-\tau}{a}\right) f(t) \mathrm{d} t
$$

Cross-correlation analysis is adopted to analyze the regional correlation between the Niño3 region and the East China Sea. It is a very simple approach to handling a veiled signal such as El Niño around the mid-latitudinal regions.

To check spatial and temporal relationships within precipitation data sets over the Pacific area, the Empirical Orthogonal Function (EOF) has been used. The primary advantage of the EOF is its ability to compress the complicated variability of the original data set into a few possible numbers of modes. The main source of this study comes from works of Kutzbach (1967) and Wallace \& Dickinson (1972).

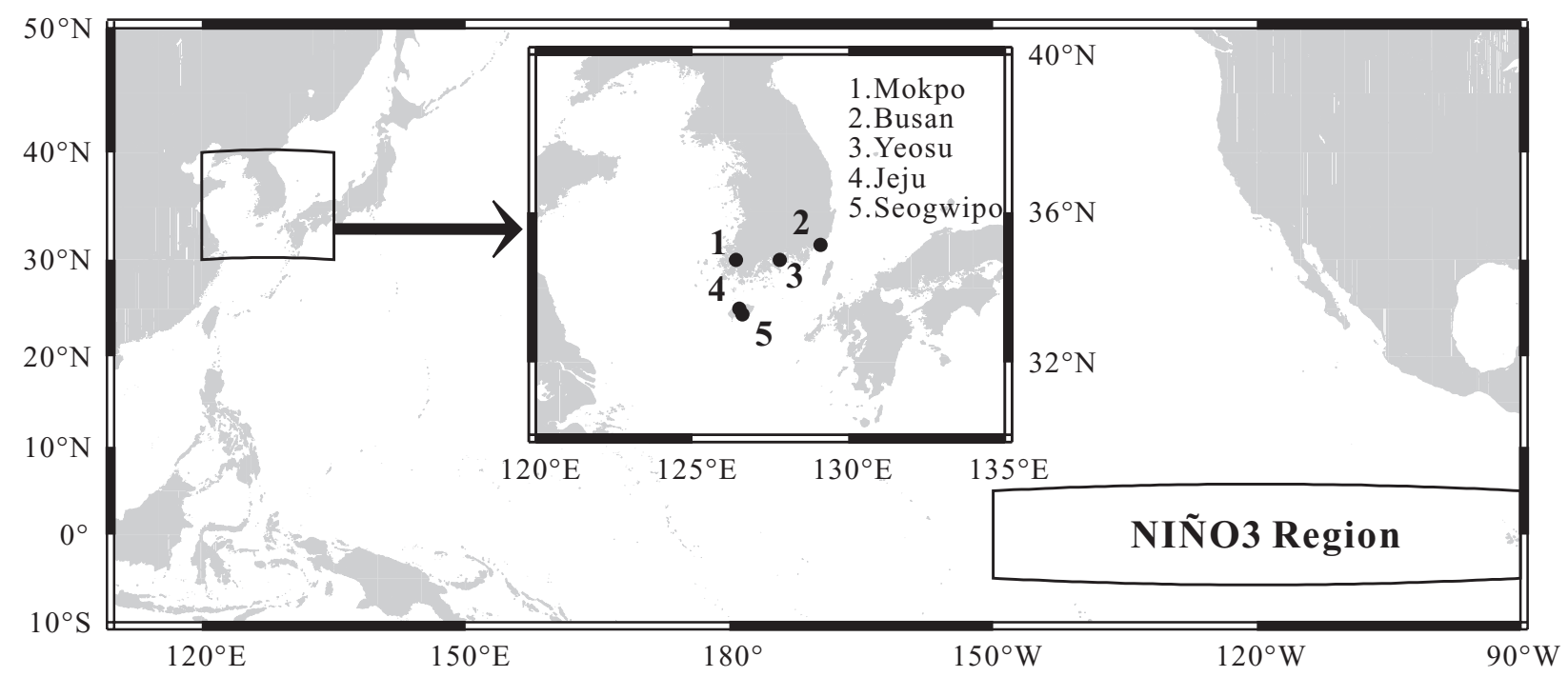

Fig. 1. Study area map. The small area shows the rain gauge stations in the southern area of Korea 


\section{PERIODICITY AT THE SOUTHERN COASTAL AREA OF KOREA}

Time series of precipitation in the southern coastal stations in Korea (Jeju, Mokpo, Busan, Seogwipo and Yeosu as shown in Fig. 1) are analyzed in order to investigate their biennial, interannual and longer time-scale variability after eliminating high-frequency signals such as strong annual fluctuation.

Spectral analysis using wavelet transform is carried out to examine the periodicity of precipitation in the same places. The right-hand panels in Fig. 2 provide the total power in a particular frequency band averaged over the entire data record. Biennial fluctuations with a 2 to $3 \mathrm{yr}$ period are found at all stations except Mokpo and Yeosu. Significant interannual cycles represent the fact that the El Niño cycle appears at all stations. Decadal cycles longer than $10 \mathrm{yr}$ are found at most stations except for Busan and Seogwipo. There is extra information in the wavelet analyses as shown in the left-hand panels. Biennial fluctuations with a 2 to 3 yr period accord with El Niño events. Also, the periods showing a strong interannual cycle correspond well with historical El Niño episodes, especially when a strong El Niño/La Niña was repeated. At the historical El Niño/La Niña episodes during 1910 to 1920 , 1940 to 1950 and 1980 to 1990 , as defined by Rasmusson \& Carpenter (1982), strong interannual fluctuations in the 4 to $8 \mathrm{yr}$ power are observed at each station. All these signals are within a $95 \%$ significant confidence level and Cone Of Influence (COI) line, indicating the limitations of the data to define variance of a particular period at a particular time of the data record. This result suggests that El Niño phenomena have significant effects on the precipitation variation at the southern coastal areas of Korea belonging to the East China Sea.
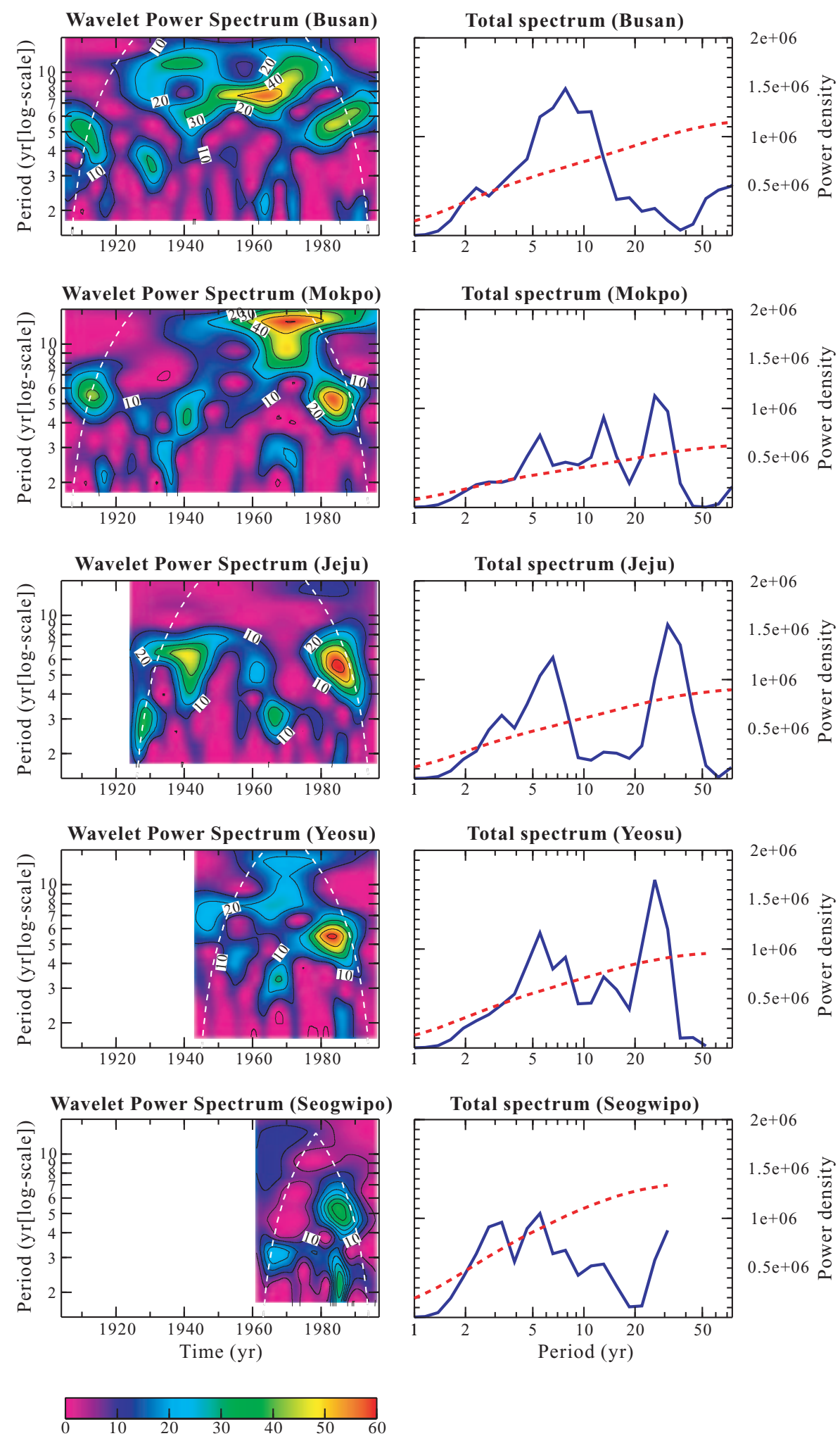

Fig. 2. Spectral analysis results. The panels on the left are the local wavelet power spectra at each station. The $x$ - and $y$-axes represent time (year) and period (year), respectively. The panels on the right are global wavelet power spectra. Dotted lines are Cone of Influence (white line on the left panels) and 95\% significance marks (red line on the left panels) 


\section{CORRELATION PATTERNS WITH EQUATORIAL PACIFIC REGIONS}

Relationships between precipitation variations in different regions are examined by computing the correlation coefficient between the Niño3 region located in the equatorial eastern Pacific and the East China Sea including the southern area of Korea (Fig. 1). The time series of precipitation of the representative values obtained from the area average of each region are shown in Fig. 3a,b. These precipitation data, which have been low-pass filtered using a cut-off frequency of $2 \mathrm{yr}$, represent remarkable quasi-periodicity on an interannual time scale. The Niño3 region shows very strong El Niño signals (Fig. 3a). The most noticeable feature is that the rainfall amount is much larger during El Niño years than in ordinary years. This is a result of the wellknown mechanism of El Niño near the Equator (Wyrtki 1975, 1985). The precipitation data of the East China Sea do not show significant El Niño signals except for strong El Niño episodes during the years of 1982-1983 and 1997-1998. The maximum value of the correlation between the Niño3 region and the East China Sea reaches up to $62.1 \%$ with a time lag of 4 mo (Fig. 3c). This implies that the increase of precipitation at the East China Sea takes place about 4 mo after the increase in the eastern equatorial Pacific during the El Niño periods.

EOF analysis was performed in order to determine what types of precipitation patterns are pronounced over the Pacific area. Fig. 4 shows the results of EOF analysis with monthly averaged CMAP $2.5^{\circ}$ by $2.5^{\circ}$ grid data which are filtered by a 24 mo Hanning filter. The first mode represents the El Niño pattern quite well near the equatorial regions and this eigenvector accounts for $41.8 \%$ of the total variance (Fig. $4 \mathrm{a}$ ). Its amplitude exhibits similar time variations to those in the Niño3 region as shown in Fig. 3a, and the spatial structure shows an east-west 'seesaw' between the equatorial western Pacific and the central (or eastern) Pacific. This pattern has little teleconnectivity between the equatorial region and the mid-latitudinal region, including the East China Sea.

The second mode associated with strong El Niño episodes explains $29.2 \%$ of the total variance (Fig. 4 b). Its amplitude particularly increases at the strong peak
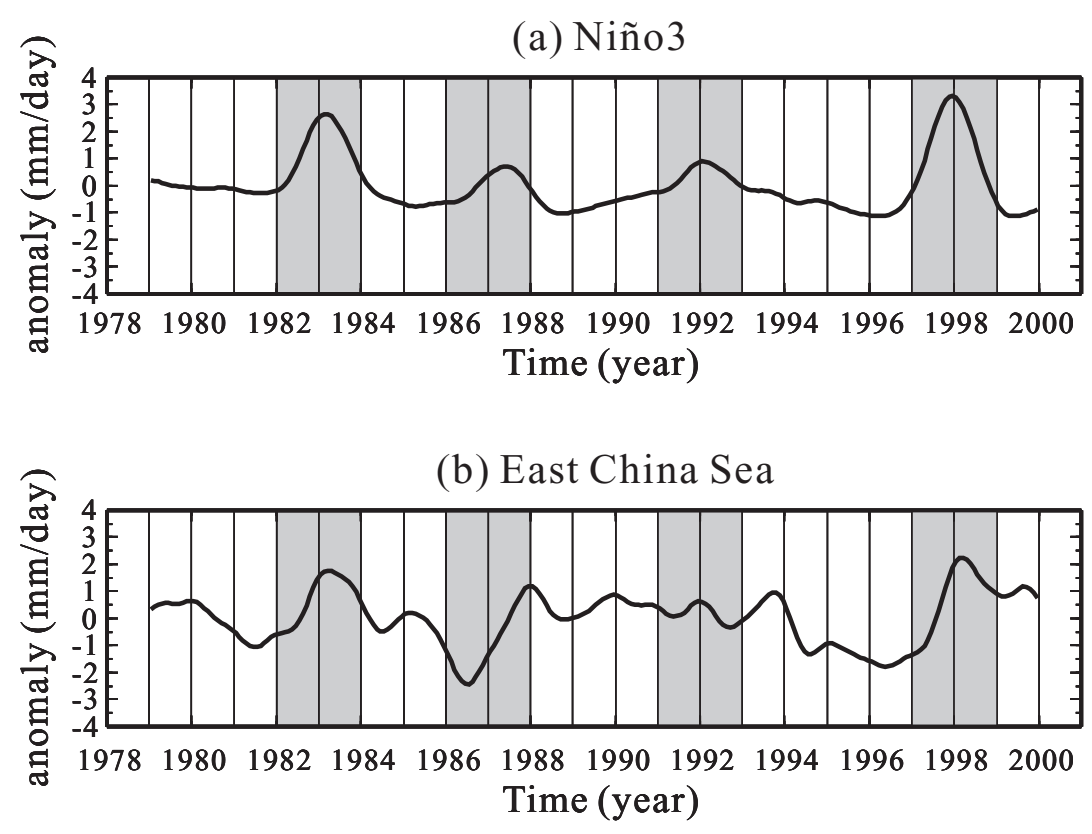

(c) Cross-Correlation ( Niño3 and East China Sea )

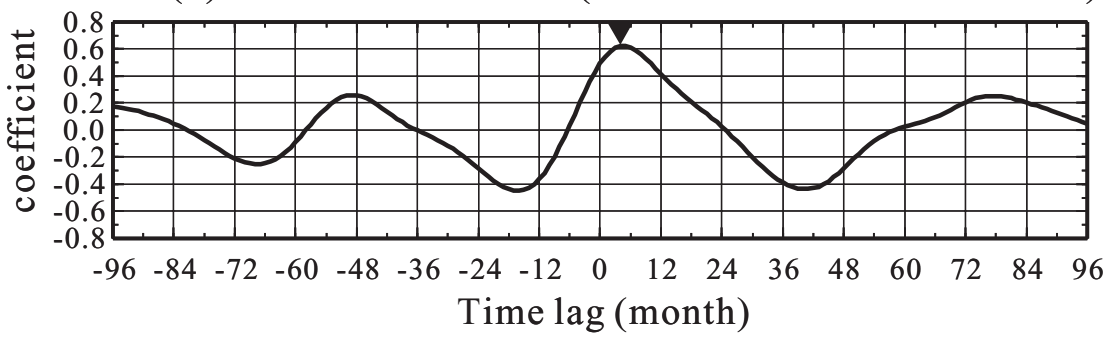

Fig. 3. Time series of precipitation convoluted by a 24 mo Hanning filter in (a) Niño3 and (b) East China Sea, and (c) cross-correlation series with a maximum delay of $8 \mathrm{yr}$, calculated between the Niño3 and East China Sea. The inverted triangle mark is the maximum correlation point and shaded regions correspond with El Niño episodes 
(a) Eigenvector and associated time series of the first mode (41.8\%)

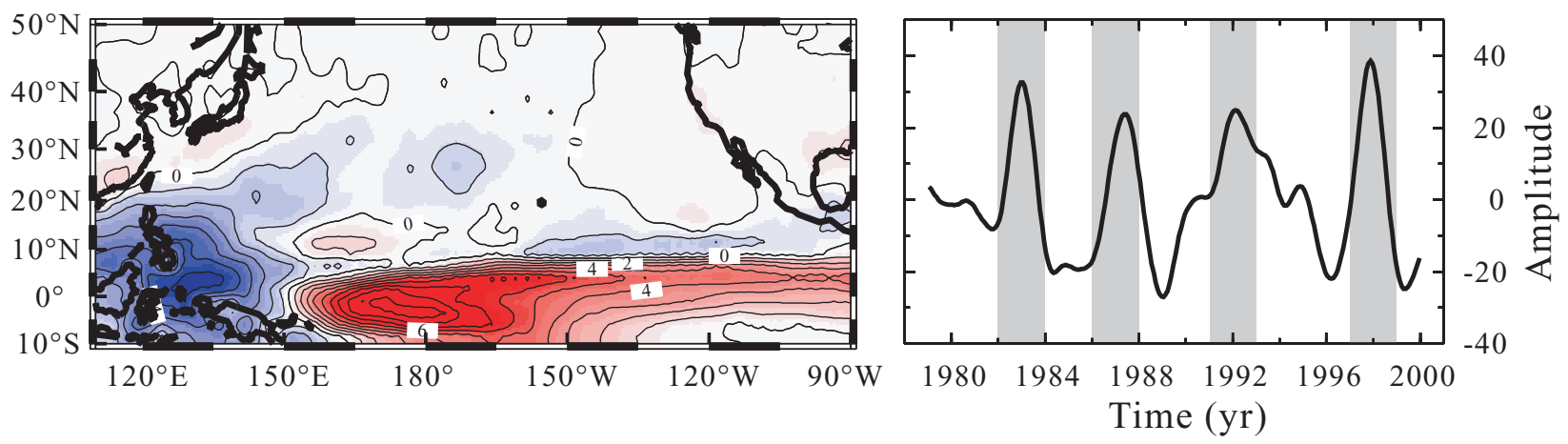

(b) Second mode $(29.2 \%)$

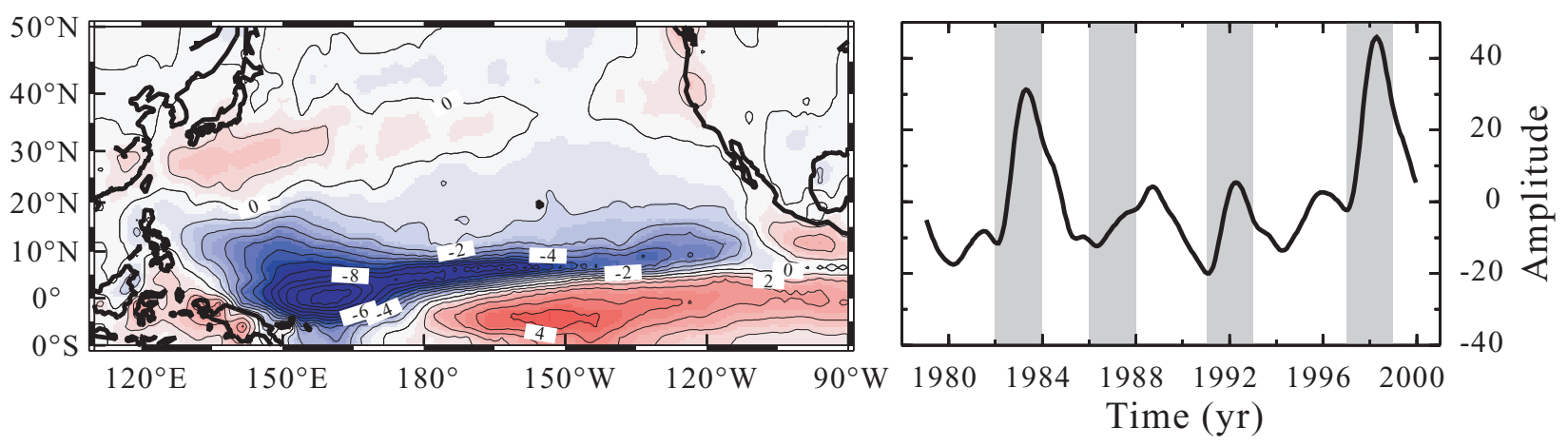

Fig. 4. The (a) first and (b) second modes of the EOF analyses of the precipitation data convoluted by a 24 mo Hanning filter. Eigenvector values indicate spatial structure of the precipitation pattern. Shaded regions in associated times series indicate El Niño episodes

during the 1982-1983 and 1997-1998 El Niños. The center showing the maximum positive eigenvector value moves further eastward than that of the first mode due to the abnormal strong El Niño signal. Another positive (wet condition) pattern occurs throughout the southern part of Japan, though its intensity is low.

It can be inferred that some teleconnections exist between the eastern equatorial Pacific (near the Niño3 region) and the East China Sea, not only from the cross-correlation and second mode of EOFs, but also from the results of wavelet spectral analysis.

\section{THE VARIATION OF UPPER LEVEL WINDS}

In order to get more cogency about spectral and correlation results, it is necessary to analyze other variables describing oceanic and atmosphere conditions relative to precipitation, since atmospheric responses to El Niño events should be systematic. That is, in every stage of evolution associated with the El Niño event, the atmospheric state should satisfy certain physical relationships. Therefore we tried to find other significant signals around the East China Sea with the reanalysis data from the NCEP. As for oceanic variables (e.g. sea level height and sea surface temperature) no direct and significant El Niño signals in mid-latitudinal regions could be found (data not shown).

Fig. 5 shows the time series of vertical velocity over the region from 7.5 to $35^{\circ} \mathrm{N}$, which is zonally averaged from 120 to $135^{\circ} \mathrm{E}$ at the $500 \mathrm{hPa}$ level of these latitudes. Near the warm-pool region located in the equatorial western Pacific, upward velocity decreases due to the low sea surface temperature during El Niño periods (Fig. 5c,d). As shown in Fig. 5a,b, we find that Hadley circulation containing the El Niño signal extends to the northward region. It shows that downward velocity was decreased during El Niño periods, especially in the years 1997-1998. The weakened Hadley circulation triggered from the tropical western Pacific may indicate the weakening tendency of the high pressure system, i.e. increasing precipitation in the mid-latitudinal region such as in the East China Sea. 
(a) $35^{\circ} \mathrm{N}$

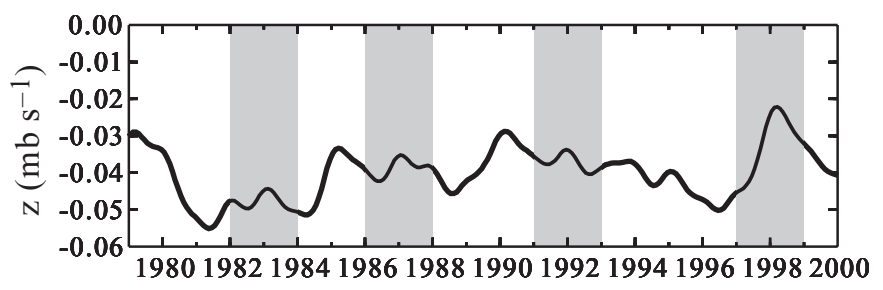

(b) $32.5^{\circ} \mathrm{N}$

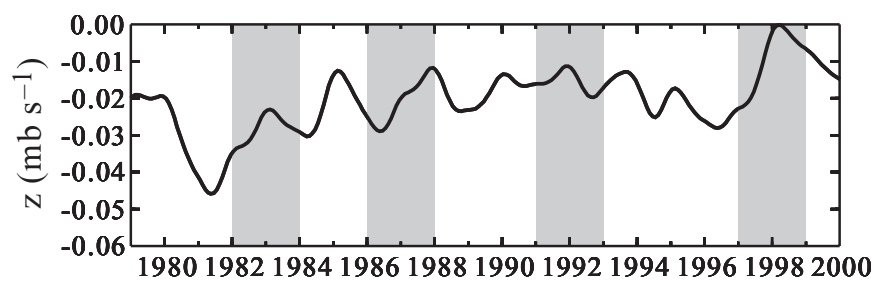

(c) $10^{\circ} \mathrm{N}$

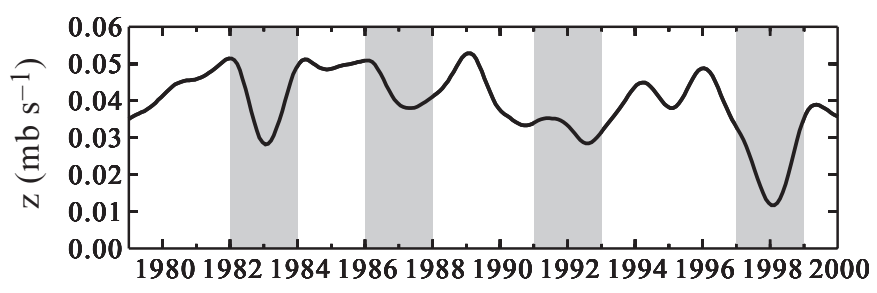

(d) $7.5^{\circ} \mathrm{N}$

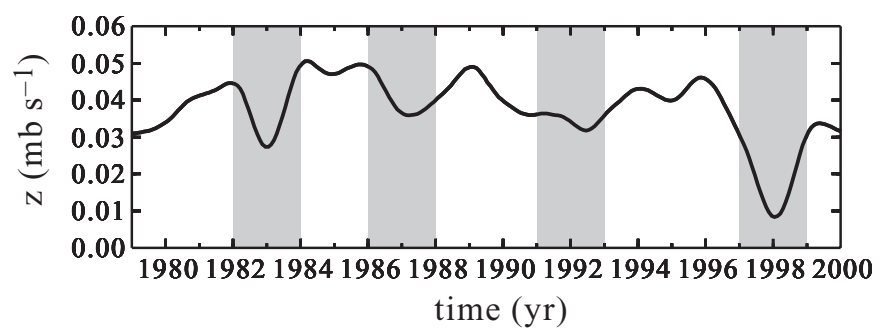

Fig. 5. Time series of upward wind speed averaged from 120 to $135^{\circ} \mathrm{E}$ at $500 \mathrm{hPa}$ in selected latitude (a) $35^{\circ} \mathrm{N}$, (b) $32.5^{\circ} \mathrm{N}$, (c) $10^{\circ} \mathrm{N}$, and (d) $7.5^{\circ} \mathrm{N}$, respectively. Shaded regions indicate El Niño periods
Other significant variations of upper level wind fields are shown in Figs. 6 \& 7. The Hovmöller diagram of meridional wind speeds, which are zonally averaged from 120 to $135^{\circ} \mathrm{E}$ in the time and latitudinal changes, is shown in Fig. 6. Red areas, indicating strengthened south winds, correspond well with El Niño episodes. This result may be related to the fact that the position of the East Asia jet stream axis is changed during El Niño periods. Fig. 7 shows the distribution of the velocity potential anomaly at the $200 \mathrm{hPa}$ level in January. Maximum (minimum) represents convergence (divergence) anomaly centers. The major convergence is found over eastern Asia (Fig. 7a). Fig. 7b-d shows an increased divergent anomaly near the eastern Pacific and also an increased convergence anomaly over the eastern part of Japan during El Niño episodes. Overall variation in the atmosphere fields over the East China Sea migrates to the east, which might cause the change of the atmospheric system, including precipitation, during an El Niño period, though its mechanism cannot be explained in detail in this study. These phenomena, in the upper troposphere during El Niño periods, have been confirmed by climatology (Trenberth et al. 1998). Variations of wind fields in the upper troposphere relative to El Niño have also been actively studied.

\section{SUMMARY AND DISCUSSION}

Periodicity, regional correlation and the spatial distribution of interannual variability of precipitation are analyzed from the Niño3 region of the eastern equatorial Pacific to the East China Sea. Most of the stations located in the southern area of Korea show a significant biennial and interannual cycle with 2 to 8 yr periodicity. As for the wavelet analysis, it was found that the periods of significant maximum power spectrum

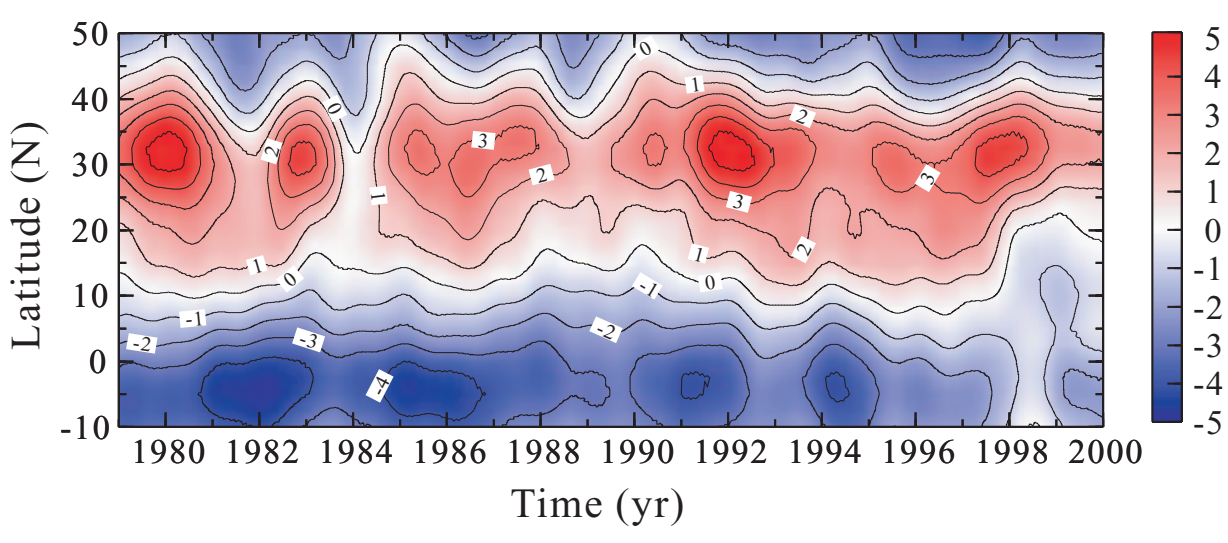

Fig. 6. Hovmoller diagram of meridional wind speed averaged from 120 to $135^{\circ} \mathrm{E}$ at $200 \mathrm{hPa}$. Red (blue) colors indicate strengthened south (north) winds 
(a) January for 21 years

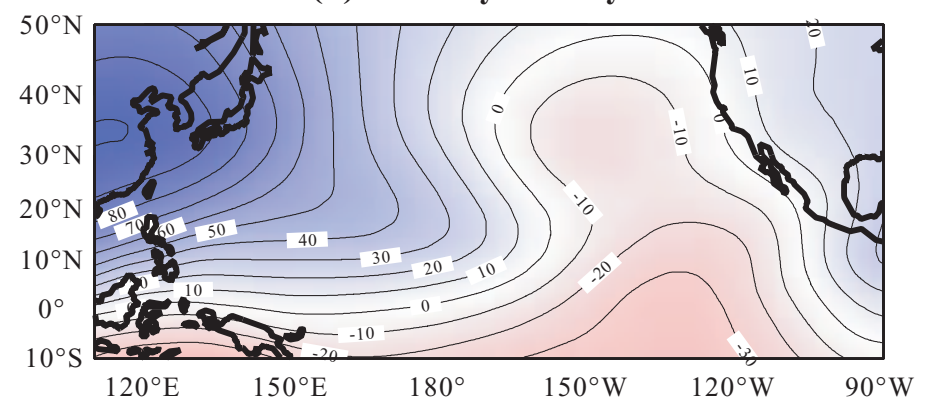

(b) January, 1983

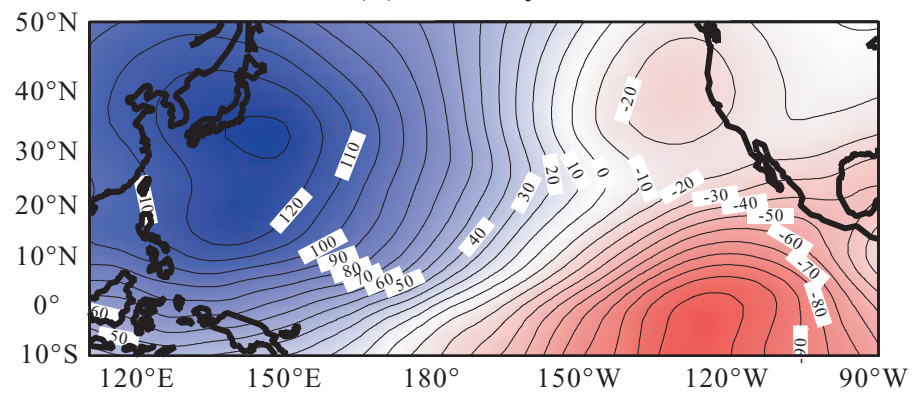

(c) January, 1992

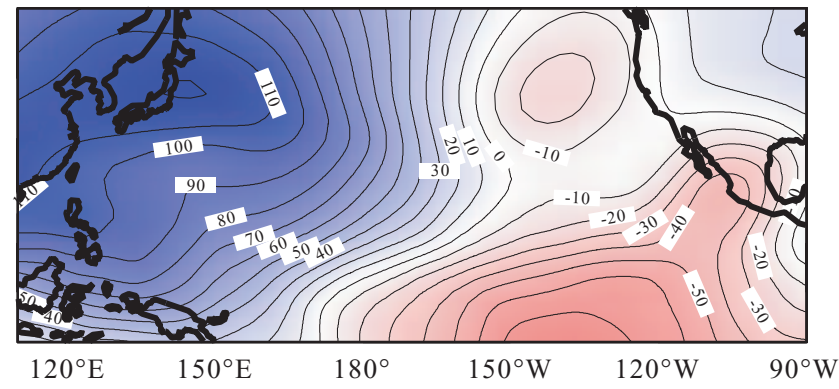

(d) January, 1998

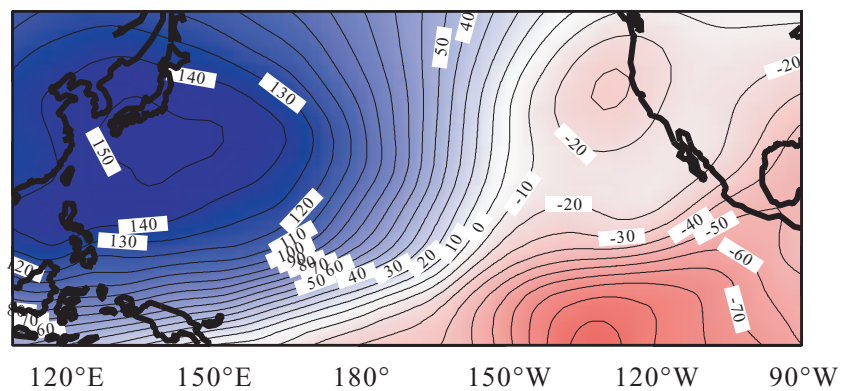

Fig. 7. (a) Velocity potential anomaly in January for 21 yr from 1979 to 1999. (b to d) Velocity potential for ENSO years: 1983, 1992, and 1998, respectively

correspond with the historical El Niño episodes, especially when a strong El Niño/La Niña was repeated (1910-1920, 1940-1950, 1980-1990). Maximum positive correlation appears between the Niño3 region and the East China Sea at a time lag of about 4 mo. This correlation tendency can be confirmed by the second mode of EOF analysis explaining strong El Niño episodes. These results suggest that, during El Niño periods, the El Niño signal contained in precipitation affects the East China Sea by a certain mechanism. The results implicate variation in upper wind fields such as Hadley circulation and East Asia jet stream.

Oceanic and atmospheric circulation and interaction on an interannual time scale have been actively studied over the last few decades both by numerical modeling experiments and by observational and theoretical research. As this study shows, data analysis approaches using diverse methods such as spectral analysis using wavelet transform, regional correlation, and EOF analysis may suggest new clues to help identify the causal mechanism, which may in turn reduce the effort necessary to determine the right direction for El Niño study.

Acknowledgements. This research is supported by a grant-inaid for scientific research projects of Dual Use Technology from the Korean Ministry of Science and Technology (MOST) in 2001.

\section{LITERATURE CITED}

Glantz M, Katz R, Nicolls N (1991) Teleconnections linking worldwide climate anomalies, Cambridge University Press, Cambridge

Horel JD, Wallace JM (1981) Planetary scale atmospheric phenomena associated with the Southern Oscillation. Mon Weather Rev 109:813-829

Kane RP (1997) Relationship of El Niño-Southern Oscillation and the Pacific sea surface temperature with rainfall in various regions of the globe. J Clim 10:1792-1800

Kidson JW (1975) Tropical eigenvector analysis and the Southern Oscillation. Mon Weather Rev 103:187-196

KMA (Korea Meteorological Administration) (1995) Changma White Book. Tongjin Munhwa, Seoul (in Korean)

Kutzbach JE (1967) Empirical eigenvectors of sea level pressure, surface temperature and precipitation complexes over North America. J Appl Meteorol 6:791-802

Lau KM, Sheu PJ (1998) Annual cycle, quasi-biennial oscillation, and southern oscillation in global precipitation. J Geophys Res D93:10975-10988

Lorenz EN (1984) Irregularity: a fundamental property of the atmosphere. Tellus 36A:98-110

Meyers SD, Delly BG, O'Brien JJ (1993) An introduction to wavelet analysis in oceanography and meteorology: with application to the dispersion of Yanai waves. Mon Weather Rev 121:2858-2866

Rasmusson EM, Carpenter TH (1982) Variations in tropical sea surface temperature and surface wind fields associated with the Southern Oscillation/El-Niño. Mon Weather Rev 10:354-384

Rasmusson EM, Wallace JM (1983) Meteorological aspects of the El-Niño/Southern Oscillation. Science 222:1195-1202

Ropelewski C, Halpert J (1987) Global and regional precipitation pattern associated with the El Niño/Southern Oscilla- 
tion. Mon Weather Rev 115:1606-1626

Stoeckenius T (1981) Interannual variations of tropical precipitation pattern. Mon Weather Rev 109:1233-1247

Trenberth KE, Branstator GW, Karoly D, Kumar A, Lau NC, Ropelewski C (1998) Progress during TOGA in understanding and modeling global teleconnections associated with tropical sea surface temperatures. J Geophys Res C7:14291-14324

Wallace JM, Dickinson RE (1972) Empirical orthogonal representation of time series in the frequency domain. Part I. Theoretical considerations. J Appl Meteorol 11(6):893-900 Webster PJ, Magana VO, Palmer TN, Shukla J, Tomas RA,

Editorial responsibility: Mitsuro Ando,

Toyama, Japan
Yanai M, Yasunari T (1998) Monsoons: processes, predictability, and the prospects for prediction. J Geophys Res 103:14451-14510

Wyrtki K (1975) El-Niño: The dynamic response of the equatorial Pacific to atmospheric forcing. J Phys Oceanogr 5:572-584

Wyrtki K (1985) Water displacements in the Pacific and genesis of El-Niño cycles. J Geophys Res C90:7129-7132

Xie P, Arkin PA (1997) Global precipitation: a 17-year monthly analysis based on gauge observations, satellite estimates and numerical model outputs. Bull Am Meteorol Soc 78:2539-2558

Submitted: March 15, 2002; Accepted: June 18, 2002

Proofs received from author(s): October 11, 2002 